\title{
NASA’s Cryogenic Fluid Management Technology Project
}

\author{
Terri L. Tramel ${ }^{1}$ \\ NASA Marshall Space Flight Center, Huntsville, AL 35812 \\ Susan M. Motil ${ }^{2}$ \\ NASA Glenn Research Center, Cleveland, Ohio, 44135
}

The Cryogenic Fluid Management (CFM) Project's primary objective is to develop storage, transfer, and handling technologies for cryogens that will support the enabling of high performance cryogenic propulsion systems, lunar surface systems and economical ground operations. Such technologies can significantly reduce propellant launch mass and required on-orbit margins, reduce or even eliminate propellant tank fluid boil-off losses for long term missions, and simplify vehicle operations. This paper will present the status of the specific technologies that the CFM Project is developing. The two main areas of concentration are analysis models development and CFM hardware development. The project develops analysis tools and models based on thermodynamics, hydrodynamics, and existing flight/test data. These tools assist in the development of pressure/thermal control devices (such as the Thermodynamic Vent System (TVS), and Multi-layer insulation); with the ultimate goal being to develop a mature set of tools and models that can characterize the performance of the pressure/thermal control devices incorporated in the design of an entire CFM system with minimal cryogen loss. The project does hardware development and testing to verify our understanding of the physical principles involved, and to validate the performance of CFM components, subsystems and systems. This database provides information to anchor our analytical models. This paper describes some of the current activities of the NASA's Cryogenic Fluid Management Project.

\section{Nomenclature}

$\begin{array}{ll}\text { ARC } & =\text { Ames Research Center, NASA } \\ \text { BAC } & =\text { Broad Area Cooling } \\ \text { CFD } & =\text { Computational Fluid Dynamics } \\ \text { CFM } & =\text { Cryogenic Fluid Management } \\ \text { Cryo Sim } & =\text { Cryogenic Simulation Tool } \\ \text { ETDP } & =\text { Exploration Technology Development Program } \\ \text { GRC } & =\text { Glenn Research Center, NASA } \\ \text { GSFC } & =\text { Goddard Space Flight Center, NASA } \\ \text { JSC } & =\text { Johnson Space Center, NASA } \\ \text { KSC } & =\text { Kennedy Space Center, NASA } \\ \text { LAD } & =\text { Liquid Acquisition Device } \\ \text { LCH4 } & =\text { Liquid Methane } \\ \text { LH2 } & =\text { Liquid Hydrogen } \\ \text { LO2 } & =\text { Liquid Oxygen } \\ \text { TVS } & =\text { Thermodynamic Vent System } \\ \text { MLI } & =\text { Multi-Layer Insulation } \\ \text { MHTB } & =\text { Multi-purpose Hydrogen Test Bed } \\ \text { MSFC } & =\text { Marshall Space Flight Center, NASA } \\ \text { NASA } & =\text { National Aeronautics and Space Administration } \\ \text { OMG } & =\text { Optical Mass Gauge } \\ \text { PVT } & =\text { Pressure, Volume, Temperature } \\ \text { RBO } & =\text { Reduced Boil-off } \\ & \end{array}$

${ }^{1}$ Deputy Project Manager, Cryogenic Fluid Management Project, Marshall Space Flight Center, VP33, Huntsville, AL 35811, Senior Member.

${ }^{2}$ Project Manager, Cryogenic Fluid Management Project, Advanced Capabilities Office, 21000 Brookpark Road/MS 86-8, Cleveland, OH, 44135, Non-member. 


$\begin{array}{ll}\text { RCS } & =\text { Reaction Control System } \\ \text { RF } & =\text { Radio Frequency } \\ \text { RMS } & =\text { Root Mean Square } \\ \text { SMiRF } & =\text { Small Muti-purpose Research Facility } \\ \text { TLI } & =\text { Trans Lunar Injection } \\ \text { TRL } & =\text { Technology Readiness Level } \\ \text { TVS } & =\text { Thermodynamic Vent System } \\ \text { ZBO } & =\text { Zero Boil-Off } \\ \Delta \mathrm{PBP} & =\text { Delta Pressure of Bubble Point }\end{array}$

\section{Introduction}

I $\mathrm{n}$ support of the U.S. Space Exploration Policy for returning to the Moon and beyond, with unique facilities and expertise, NASA and its partners are developing and testing cryogenic fluid propellant technologies that will meet the need for cryogens in propulsion system on long-duration missions, ground operations, and long-term lunar surface systems. The CFM Project Team led by NASA Glenn Research Center (GRC) in partnership with Marshall Space Flight Center (MSFC), Johnson Space Center (JSC), Ames Research Center (ARC), Goddard Space Flight Center (GSFC), Kennedy Space Center (KSC) and industrial partners are conducting a focused technology development effort to advance cryogenic fluid management systems. The CFM Project is a customer need driven project, emphasizing efforts that are enhancing and critical to NASA's Constellation Program's Projects in the areas of cryogenic storage, cryogenic distribution, cryogenic low-gravity propellant management, and cryogenic transfer and handling systems. The CFM project focuses on the development of cryogenic storage systems, low-gravity propellant management systems, cryogenic transfer and handling technologies needed to provide necessary data and relevant experience to support informed decisions on implementation of cryogenic systems into the Space Exploration Architecture. Successful implementation of high performance cryogenic systems on long-term missions requires 1) the knowledge of the physics/thermodynamics through the understanding of existing data and acquiring knowledge gaps through ground-based testing and modeling, and 2) the development of thermodynamic control devices to aid in designing a cryogenic system that meet the mission requirements.

The last two years, the NASA cryogenic fluid management technology activities have undergone a rejuvenation process, due to the large, diverse needs across the Exploration Architecture ${ }^{1}$. Existing activities under different Exploration Technology Development Programs' (ETDP) Projects, and new activities have been brought together under one new Project, the Cryogenic Fluid Management Project. The state of the art in cryogen application is once again being stretched by the exploration into space. To better address these greatly diverse needs, the CFM Project organized itself into three basic areas for technology development: CFM System Technologies, CFM Supply Systems, and CFM Transfer Systems. This paper will give a short overall summary of the major technology development areas of the project, and only briefly touch on a selected few of the recent accomplishments.

\section{Cryogenic Fluid Management System Technologies}

The objectives of CFM Systems Technology are to collect, define and document Exploration program CFM technical requirements, identify collaborative testing opportunities, evaluate and predict performance of integrated CFM systems, and assist in Exploration CFM systems preliminary designs. This area includes development of CFM requirements; risk management; CFM systems analyses and trade studies; evaluation and demonstration of integrated CFM subsystems; ground test facility management, safety, and oversight; and coordination with other ETDP projects and Constellation customers. One major activity includes identifying and developing analytical tools to enable the prediction of the integrated performance of CFM components and subsystems, and interactions under various conditions (ground loading, low-gravity, launch ascent, abort, and long duration). The other major activity includes CFM system level trade studies, including those lead by CFM customers in which CFM is asked to support. The function of this technology area fundamentally, it is to bring together all system analysis tools and integrated system tests into one place to maximize the synergy and reduce cost.

Understanding the CFM system as a whole will lead to more efficient system designs of the launch system, which includes the tanks, feedlines, instrumentation, pumps, valves, the propulsion systems, and the payload and/or crew. The more confidence in your knowledge of the boil-off of your cryogens (zero with minimal mass increase is the ultimate goal), the less margin you have to include. That means more payload can be delivered to orbit and 
ultimately to the lunar surface. Making the CFM systems as simple as possible, makes the entire launch system safer too. Less components, or less moving parts ultimately results in less risk for the payload or crew, so the CFM Project team continually looks for technology solutions that simplify the entire CFM system. Additionally, cryogens are in the trade space for lunar surface operations. Primarily for mobile operations, storage, transfer, and handling are key technology areas that need to be addressed. While on the lunar surface, crew will be traversing to various locations on rovers, which may be carrying small tanks of cryogens for rover fuel. These small systems need to be understood similarly with propulsion systems.

\section{A. System Analytical Tools}

The overall goal of the system analytical tools technology development is to identify and develop analytical tools to enable the prediction of the integrated performance of CFM components and subsystems under various conditions, and to conduct trade studies of CFM subsystems to assess technology gaps. The component and/or subsystem models are developed under either CFM storage systems or CFM transfer systems, but brought together to enable the entire system to be analyzed and different systems to be compared on a system level thereby ensuring that the individual component performance actually benefits the entire systems, including tanks, feedlines, and individual components such as Thermodynamic Vent System (TVS), and Radio Frequency (RF) mass gauges.

CryoSIM is a cryogenic storage system simulation tool the development of which is driven by the need to standardize and integrate a wide variety of existing in-house cryogenic codes that use a variety of algorithms with varying degrees of documentation, verification, \& availability. The main goal of CryoSIM is to standardize a consistent set of assumptions, data, tools, etc., and generate conceptual design results in an overall structured analytical approach. Required documentation will include each contributed code's capabilities, limitations, assumptions and validations. The development of CryoSIM is a multi year task, with fiscal year 2008 being its initial year with laying the ground work for future development by assessing the current NASA CFM analytical capabilities and needs. The resulting requirements were:

1) Vehicle-level thermal modeling and CFM thermal modeling in one tool

2) Build around an industry-standard thermal analysis tool

3) Use the best modeling features from existing tools

4) Retain legacy modeling capabilities

5) Validation and documentation from each contributor

6) Consensus in analytical approaches, methods and data

7) Centralized version control and archiving

8) Flexibility, growth and compatibility with other codes

The thermal analysis platform selected for this effort is Thermal Desktop with RadCAD, FloCAD and SINDA/FLUINT ${ }^{2}$. Thermal Desktop provides the graphical user interface and conduction network modeling, RadCAD provides the thermal radiation network modeling, and FloCAD provides the fluid network modeling. SINDA/FLUINT is the numerical analyzer. One of the most attractive features of this approach is the ability to integrate and use existing or new user codes as the need arises. The current plans include the addition of such user codes as system hardware mass estimation, heat leak estimation, boiloff estimation and convective cooling. The current plan is to have CryoSIM fully operational around the beginning of 2011. It is currently functional with some capability and is already being used to support Exploration trade studies.

\section{B. Low-G Fluid Dynamics}

The purpose of this activity is to develop computational fluid dynamic (CFD) models to support prediction of CFM component and subsystem performance for propulsion systems during the dynamic low-g fluid conditions of space. In particular interest is that of slosh of the propellants and venting of the propellants during flight. How do these two internal physical phenomena affect the entire space transportation system? The short term interest of the project is that of propulsion systems, but in the long term the same concerns apply on the lunar surface. The approach for this technology is to develop in parallel in-house NASA capabilities and external capabilities at universities and industry.

\section{Integrated Tests and Demonstrations}

There have been many decades of work in the CFM technology area, both in the integrated propulsion feedsystems and ground operations systems. Two sets of integrated tests/demonstrations are currently planned. In some cases, these integrated tests/demonstrations will be of subscale systems and in some cases they may be close to 
full scale (depending on the parallel development of some propulsion systems). In either cases, these tests are the accumulation of years of component/subsystem development. This is the best hardware simulation that can be done, short of a system flight test or actual implementation in the launch ground support system.

1) Integrated Feedsystem Tests

The goals of the Integrated Feedsystem are to perform thermal vacuum tests with an integrated representative tank CFM-Feed System prototype CFM components/subsystems to characterize the interrelationships of these components/subsystem and to validate the integrated performance against the system analytical tools. In many cases this will also be the first time that these components physically come together in a vacuum system. At this time the CFM Project is looking at testing two cryogenic fluids in three different vacuum chambers, one at the Small Muli-Purpose Research Facility, SMiRF, at GRC and two at Test Stand 300 at MSFC. Fluids planned for integrated feedsystem testing at this time are Liquid Methane (LCH4), and Liquid Hydrogen (LH2).

\section{2) Integrated Ground Operations Demonstration}

The cryogenic ground operations at KSC are very large, complex and in some cases were originally designed and built for the Apollo Program. The cost of propellants is based on what is produced at the factory and not what is actually pumped into the launch vehicle at the pad. The current capability is atmospheric venting of LH2 and LO2 launch site storage boil off gases replenish with delivery from supplier. The goal of this technology is to have zero loss LH2 and LO2 launch site storage and elimination of transfer line fluid heating. Technology being consider for development are refrigeration systems to reliquify LH2 and LO2 launch site storage boil off gases, improved LH2 pumping efficiency and transfer line conditioning, and to develop non-invasive transfer line pressure and flow sensors. It is planned to integrate refrigeration hardware, pumps and transfer line segment into scaled launch site test facility and conduct ground operation demonstrations.

The current plan is that as after the CFM component and subsystem are developed in the storage and transfer areas, then hardware prototypes will be brought together into the integrated tests/demonstrations. Some initial activities that are occurring in the year 2008 are some purchases of long lead items. For example a new high pressure cryogenic tank is being procured, and initial trades are beginning in ground operations area.

\section{Advanced Insulation Systems}

Making insulation for all cryogenic systems lighter, more thermally efficient and more robust is needed for all cryogenic applications, whether on the earth, in space or on the lunar surface. The initial goal of the CFM Project is to address the cryogenic advanced insulation technologies that have the potential to be cross-cutting in application to various vehicles, ground operation equipment and lunar systems applications. After some initial cross cutting studies, specific applications will be developed in the storage and transfer areas. The goal here is to begin in fiscal year 2009 with a survey of the state of the art in advanced insulations systems, including site visits by the CFM technical team. The current plan ramps up to a large technology development in fiscal year 2010 with coupon characterizations. Ultimately the goal is getting to manufacturing large amounts of insulation for application on large test tanks.

\section{CFM Storage Systems}

The objectives for the CFM Supply System are to design and test advanced technology subsystems to store and distribute cryogens that will meet the need for long-duration missions. This WBS element includes: 1) Liquid Storage to enable the long-term storage of cryogens in one-g and low gravity environments with minimal fluid losses, 2) Liquid Supply to provide thermally efficient, delivery of a single phase fluid to the CFM Transfer System (WBS 4.0), and 3) Instrumentation to enable accurate measurement of cryogenic liquid mass in low-gravity storage tanks without propellant settling, and to enable the ability to detect in-space leaks from the Supply System.

\section{A. Liquid Storage}

The objective of CFM Liquid Storage is to enable the long-term storage of cryogens in one-g and low gravity environments with minimal propellant losses. The storage element of the CFM Supply System includes thermal control and pressure control. Thermal control is defined as insulation systems, passive systems, and active systems. Pressure Control includes Thermodynamic Vent Systems and mixing. This area includes the development of design 
tools and models for safe long-term storage of cryogenic fluids; and cryogenic storage design, component testing and subsystem performance testing. This area is what defines the effort to manage, design, analyze, develop, and test a thermal and pressure control system for cryogenic tank systems. The effort will analytically define the type of thermal control system (active or passive) to be used for LO2, LH2, and LCH4 under various thermal conditions and mission profiles (ground loading, quiescent, launch ascent, Trans Lunar Injection (TLI), abort, long duration). Analytical models/tools will be used to assess performance of a passive thermal and pressure control system.

Storage component analytical modeling is being developed in two areas: create and exercise lumped-parameter analysis models, and develop computational fluid dynamic models using commercial and in-house codes for selfpressurization and pressure control using ground-based experiments. This activity is being performed in parallel by NASA in-house activities, university activities, and our industry partners. These models are being evaluated against existing databases, such as the Saturn 4B test data and recent NASA vacuum chamber test data. Liquid Methane (LCH4) testing was conducted at the Marshall Space Flight Center (MSFC) using the multipurpose hydrogen test bed (MHTB) to evaluate the performance of a spray-bar TVS with subcooled LCH4 and gaseous helium (GHe) pressurant ${ }^{3}$. Thirteen days of testing were performed in November 2006, with total tank heat leak conditions of about $715 \mathrm{~W}$ and $420 \mathrm{~W}$ at a fill level of approximately $90 \%$. A total of 23 TVS cycles were completed. The TVS successfully controlled the ullage pressure within a prescribed control band. A liquid subcooling operation demonstrated the capability of the TVS to remain on for long durations (over 14 hours of continuous operation) and to reduce the liquid saturation pressure to a desired target. The TVS was also successful at maintaining liquid saturation pressure within a control band. These accomplishments were significant since they demonstrated the capability of the TVS to deliver a required temperature and pressure to the engine inlet. During a brief special test, the TVS was used to reduce ullage pressure without the recirculation pump, demonstrating a potential contingency mode.

One recent accomplishment was the completion of the tube to tank test at ARC. The test data gathered validated the previously developed broad area cooling modeling correlations for distributed cooling tubes attached directly to cryogenic tank walls. The objective of this effort was to validate thermal fluid models that have been employed in the development of distributed cooling and Broad Area Cooling (BAC) design concepts and trade studies. The significance of this work is that $\mathrm{BAC}$ will allow one or a few single cryocoolers to effectively cool a large cryogenic tank to achieve Zero Boil Off (ZBO) or Reduced Boil Off (RBO) cryogen storage while preventing stratification of cryogen in the tank. This technology is applicable for on-orbit, in-space, and lunar/planetary surface applications as well as for scientific missions where the cryocooler is located remotely from the heat load. Figure 1 shows the physical test setup.

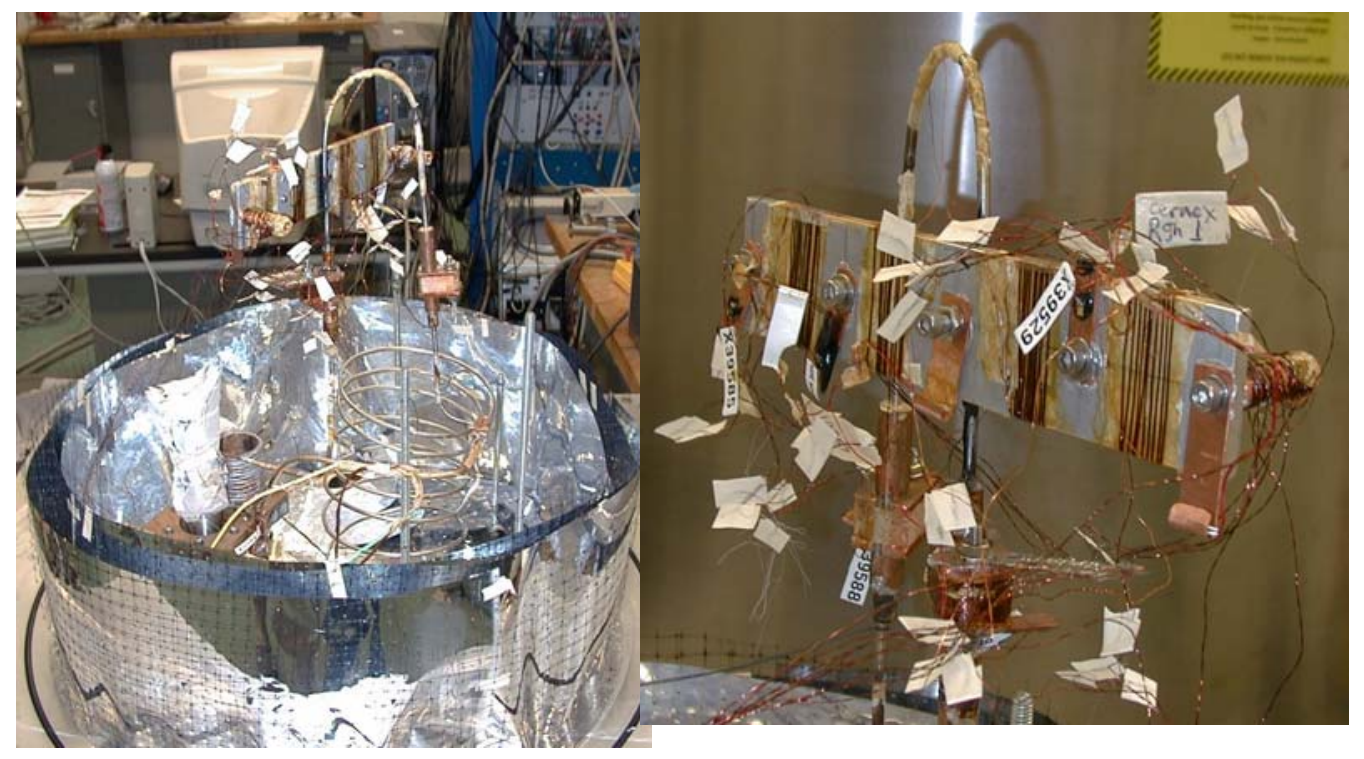

Figure 1. Tube-to-Tank Experiment Setup and Test Section Close-up 


\section{B. Liquid Supply}

The objectives of the CFM Liquid Supply System are to provide thermally efficient delivery of a single phase fluid to the CFM Transfer System. This area of technology development involves development and test of liquid acquisition devices, including settling and outflow, analysis of data on performance of screen channels, and Helium pressurization validation studies. Analytical models/tools are developed to assess performance and the mechanical integration of the acquisition devices and pressurization with a test tank under various thermal conditions and mission profiles (quiescent, launch ascent, TLI (Trans Lunar Insertion), abort, long duration).

When transferring propellant in space, it is most efficient to transfer single phase liquid from a propellant tank to an engine. In low gravity where fluid is not centered over the tank outlet, withdrawing single-phase fluid becomes a challenge. One type of Propellant Management Device, a liquid acquisition device (LAD) takes advantage of capillary flow and surface tension to acquire liquid. Previous experimental test programs conducted at NASA GRC and MSFC have collected LAD data for a number of cryogenic fluids, including: liquid nitrogen (LN2), liquid oxygen (LO2), liquid hydrogen (LH2), and liquid methane (LCH4). Previous tests with LCH4 indicated that the standard method for calculating bubble point appeared to under-predict $\triangle$ PBP for subcooled LCH4. A kinematic viscosity term had been proposed to improve the correlation between observed test data and predictions, and additional testing over a broader range of fluid conditions was desired. This test program with subcooled LO2 was performed to better understand how LAD performance is affected by these factors.

Based on results from these tests, it appears that that using the previously proposed normalized viscosity term is not appropriate. Differences between test data and predictions are better explained by considering the LO2 conditions at the screen liquid/vapor interface and the effect of helium pressurant gas on these conditions. The significance of these findings points out that the largest potential error in predictions occurs with the coldest liquid, and diminishes as liquid pressures and temperatures increase.

Bubble Point vs Surface Tension

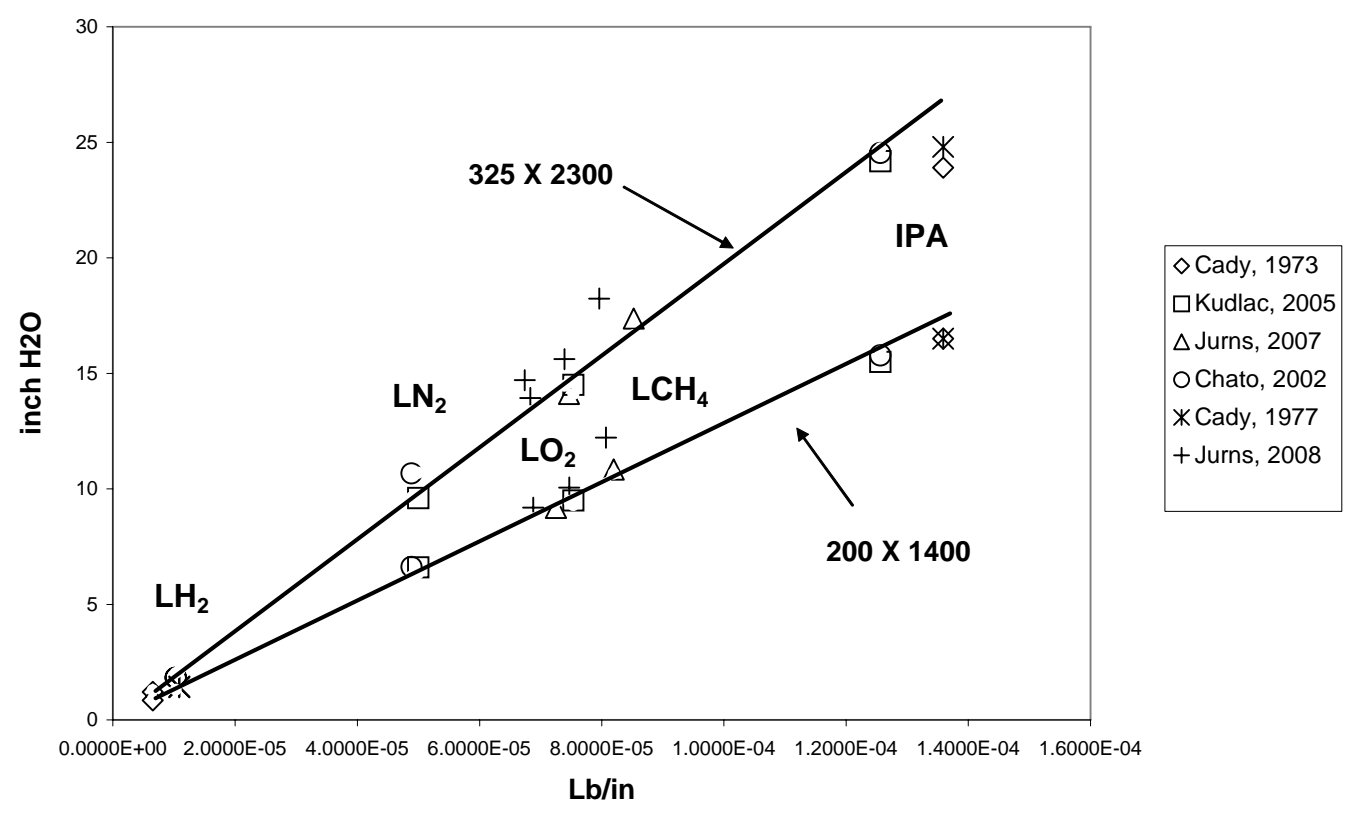

Figure 2. Summary of Bubble Point Data for LH2, LN2, LOX, and LCH4 


\section{Liquid Supply Instrumentation}

The objective of CFM instrumentation is to enable accurate measurement of cryogenic liquid mass in lowgravity storage tanks without propellant settling, and to enable the ability to detect in-space leaks from the Supply System. This effort includes, NASA development and test of RF and PVT (pressure, volume, temperature) low-g mass gauging concepts using a variety of cryogens, NASA verification testing of contractor developed optical mass gauge with LO2, development of analytical models to predict performance of settled and low-gravity mass gauging concepts. NASA will also assess and test settled mass gauging techniques. Given that a low-g, non settling gauging is more challenging to developed, NASA will continue the development of settled gauging techniques as a option. Another area of technology development is the area of leak detection sensors for in-space use and on the ground use. For obvious safety reasons, the earliest detection of any propellant leak allows for the earliest remedy to be applied, or gives the crew the maximum number of options for risk mitigation.

Apollo conducted propellant management by having a large margin of extra propellant and settling its tanks, that is applying propulsive forces with a smaller propulsion system (like a reaction control engine) to force the mass in the larger tanks to the desired position in the larger tank. The CFM development goal of allowing fluid management functions without settling propellants provides major propulsion system benefits by simplifying vehicle operations, reducing system mass, and expanding operational and architectural options. One of these operations is that of propellant gauging, determining how much propellant is left. Imagine having to have your car moving to tell how much gas is left, or almost having to calculate how much gas is left in your tank prior to each turn of the wheel. Developing technology to determine the amount of propellants are left in the tanks, without having to burn any propellant, is the objective of mass gauging in low $g$ environments.

The verification of the three mass gauge options is a vital part of the effort ${ }^{4}$. The year was busy with testing of three types of mass gauges to increase the technology readiness level (TRL) in a size tank relevant to one potential application. The objective of these test series was to evaluate the accuracy of Radio Frequency (RF) Optical Mass Gauge (OMG) and Pressure-Volume-Temperature (PVT) mass gauge technologies in a liquid oxygen environment. The results of the both RF and PVT mass gauges indicate good accuracy; RMS error less than $2 \%$ full-scale. The OMG data is still being assessed at this time.

\section{CFM Transfer Systems}

Highly reliable, robust systems are needed to support launch processing as well as a sustained human and robotic exploration on the surface of the Moon. These systems will require cryogenic fluids that will have to be replenished from supplies either brought from Earth or produced on-site. The objectives for the CFM Transfer System are to design and test advanced technology subsystems to transfer and handle cryogens that will meet the need for longduration missions. This element includes the technical and management efforts of directing and controlling design and analyses for the CFM Transfer System, which include liquid transfer and fluid handling elements.

\section{A. Liquid Transfer}

The objective of Liquid Transfer is to enable thermally efficient, single-phase, distribution of liquid from the CFM Supply System. This area includes the design, analysis, development, and test of a propellant distribution system for the cryogenic Reaction Control Systems (RCS) tank chill down and no-vent fill processes, and fluid interfaces, and including low-heat leak quick disconnects. One vital area of development includes the effort to manage, design, analyze, develop, and test of cryogenic liquid transfer devices and processes for earth-based, low gravity, and long duration use. The project team at JSC has been analyzing and developing technologies for delivering properly conditioned cryogenic propellants to the RCS engine inlet interface through long, small diameter feedlines. The objectives of this cryogen transfer activity is to test quiescent mode cryogenic RCS manifold with TVS to demonstrate that the thermal performance meets or exceeds inlet condition requirements for RCS engines. The testing evaluates whether or not the thruster simulator duty cycle tests to verify manifold chill in response times meet or exceed inlet condition requirements for RCS engines's, and to demonstrate feed system feasibility for incorporation into future integrated feed system thruster testing.

Phase I was completed and implemented full scale RCS manifold/TVS assembly and subscale tank in appropriate space vacuum environment, and gathered system heat leak information and determined proper orifice size to condition the manifold line. Phase II is also complete and used the information gathered in Phase I to improve the system's performance, and an engine simulator pod was incorporated to study the effects of heat soak back from engine simulators on cryogen fluid management. Both phases were successful and demonstrated that with manifold conditioning via simulator thruster cycling: 1) no TVS needed during simulated $3 \mathrm{lbm} / \mathrm{sec}$ engine firings, 2) demonstrated long term quiescent mode conditioning with TVS, and demonstrated the feasibility of TVS 
for integrated system level altitude testing. Suggestions for improving the cryogenic feedline performance by improving the efficiency of the TVS configuration 1) by increasing the contact with manifold near engine simulator pod, 2) close couple TVS orifice to engine simulator manifold (minimize fittings), 3) implement piezoelectric TVS valve for dynamic flow control and improve MLI blanket design.

\section{B. Fluid Handling}

The objective of the Fluid Handling task is to process the fluid within the CFM Supply Systems to enable thermally efficient transfer. Technologies addressed in this technology area includes Densification/Subcooling, and Liquefaction, and includes the effort to manage, design, analyze, develop, and test cryogenic handling processes for earth-based, low gravity, and long duration use. One activity in this area is the development of dust-tolerant quick disconnect of cryogenic lines.

The objective of the dust-tolerant disconnect is to develop and test a first generation prototype quick disconnect with integrated dust protection and low heat leak, capable of servicing a liquid air extra-vehicular activity suit. Dust protection includes both electrostatic as well as mechanical protection. Development of a dust tolerant disconnect is important because there exists the requirement to perform fluid servicing of various systems on the lunar surface, which includes mating of quick disconnects (with low heat leak). Dust contamination of these open fluid systems is a serious safety and reliability concern, because dust can cause failure of mechanisms and seals, and internal contamination increases the risk of combustion in oxygen systems. The recent accomplishments include field testing of mechanical system at Desert Rats (shown in Figure 3), and the lab testing of the electrostatic protection technology.

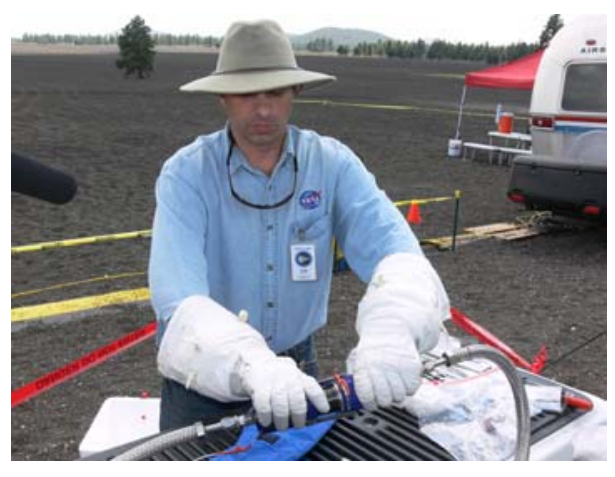

Figure 3. The Field Testing of a Dust-Tolerant Quick Disconnect.

\section{Transfer Instrumentation}

The objective of CFM transfer instrumentation is to evaluate the technology options available, and choose one or two to develop to a technology readiness level of 6 (prototype testing in a simulated environment) before the Flight Project's Preliminary Design Review. The object of this area is to develop technology for cryogenic ground operations systems leak detection, propulsion system leak detection and lunar surface systems leak detection. This activity will start at the end of 2008 with a small effort.

\section{Summary}

This paper presented the CFM Project plan for developing cryogenic fluid management technologies needed for to return to the moon and stay on the lunar surface. In addition a top level summary of some of the cryogenic fluid management technologies recent results were presented. In the past, these technologies were developed separately for specific propulsion or ground operations applications. Now these technologies are being developed under one project being the knowledge and expertise together to better serve NASA's needs, especially those of long term lunar stays.

The CFM project addresses a wide range of technical issues associated with managing cryogens in terrestrial and low gravity environments. This diversity makes it difficult to characterize the technology with a simple or single metric. Many parameters have strong influences on performance, applicability and the benefits of a given technology element, and the CFM elements are at different levels of maturity. Passive thermal and pressure control 
are ready for near-term applications while liquid acquisition, mass gauging, active thermal control and feedline conditioning require further development. Characterizing the combined influence of the CFM subsystems on component performance in a fully integrated system tests is a common development need, both in ground operations systems and space application systems. In the near term, system analysis, component and subsystem development is

the project focus. Starting in 2010 the focus becomes pulling all the technologies into two large integrated system tests, both designed to demonstrate the maturity needed to implement these new technologies into operational ground and flight systems.

\section{Acknowledgments}

The authors would like to thank the Exploration Technology and Development Program Office for their continued support in funding the work to enable NASA's U.S. Space Exploration Policy, and the CFM Project team members across six NASA centers, several universities, and several industry partners for their hard work and dedication on this project.

\section{References}

${ }^{1}$ Motil, S.M., Meyer, M.L., Tucker, S.P., "Cryogenic Fluid Management Technologies for Advanced Green Propulsion Systems", AIAA-2007-343

${ }^{2}$ Cullimore \& Ring Technologies, Inc., Boulder, CO.

${ }^{3}$ Flachbart, Robin H., NASA, ETDP-GRC-CFM-FY08_RPT-001, Final Report, December 21, 2007

${ }^{4}$ Zimmerli, G.A., Vaden, K.R., Herlacher, M.D., Buchanan, D.A., Van Dresar, N.T., "Radio Frequency Mass Gauging of Propellants", NASA TM-2007-214907 and AIAA 2007-1198 


\section{NASA's Cryogenic Fluid Management Technology Project}

\section{Space 2008 Conference San Diego, California}

Terri Tramel, CFM Deputy Project Manager, MSFC Sue Motil, CFM Project Manager, GRC 
$\checkmark$ Project Objectives

$\checkmark$ Project Introduction

$\checkmark$ Project Structure

$\checkmark$ Project Content

- CFM System Technologies

o CFM Storage Technologies

- CFM Transfer Technologies

$\checkmark$ CFM Recent Accomplishments

$\checkmark$ Questions

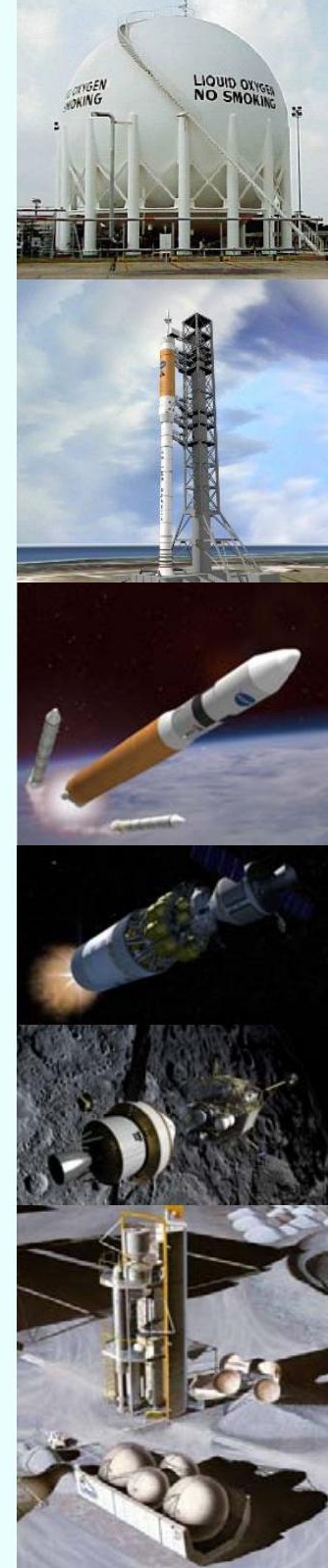




\section{Disclaimer}

We are a technology development project, addressing a broad scope of activities. In no way is anything presented here specific toward any NASA Flight Project, either flying or currently in development. 


\section{CFM Project Objectives}

The Cryogenic Fluid Management (CFM) Project's primary objective is to develop storage, transfer, and handling technologies for cryogens that will support the enabling of high performance cryogenic propulsion systems, lunar surface systems and economical ground operations.

- The two main areas of concentration are analysis models development and CFM hardware development.

o The project develops analysis tools and models based on thermodynamics, hydrodynamics, and existing flight/test data: ultimate goal being to develop a mature set of tools and models that can characterize the performance of the pressure/thermal control devices incorporated in the design of an entire CFM system with minimal cryogen loss.

o The project does hardware development and testing to verify our understanding of the physical principles involved, and to validate the performance of CFM components, subsystems and systems. This database provides information to anchor our analytical models.

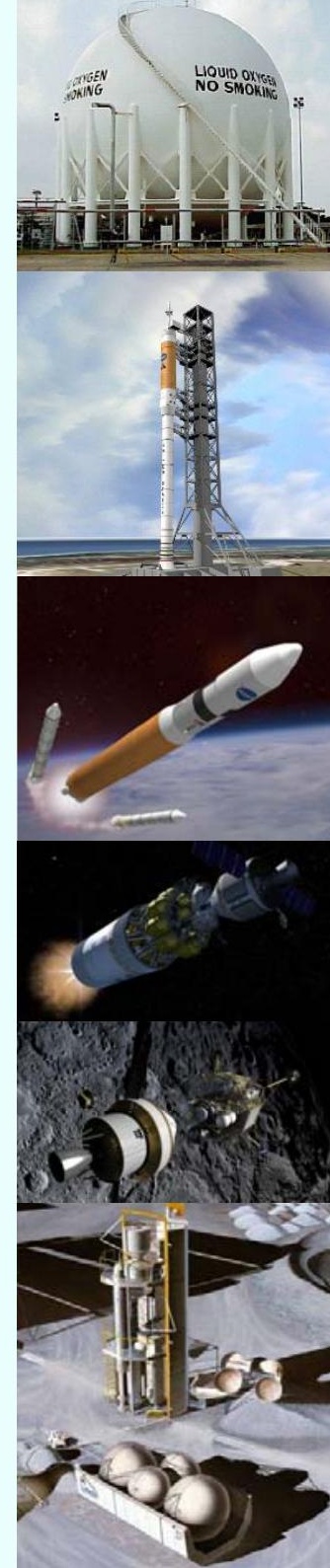




\section{Project Introduction}

The CFM Project is a customer need driven project, emphasizing efforts that are enhancing and critical to NASA's Constellation Program's Projects in the areas of cryogenic storage, cryogenic distribution, cryogenic low-gravity propellant management, and cryogenic transfer and handling systems.

o Glenn Research Center leads-support from Marshall Space Flight Center, Johnson Space Center, Ames Research Center, Goddard Space Flight Center, Kennedy Space Center, several industry partner and several university partners.

- Provides CFM technologies needed to support informed decisions on implementation of cryogenic systems into the Space Exploration Architecture.

- CFM Project under went a recent rejuvenation process

- Diverse needs across the Exploration Architecture

- Bring together existing activities under different Exploration Technology Development Programs' (ETDP) Projects

- CFM Project Focuses

- Development of cryogenic storage systems

- Low-gravity propellant management systems

- Cryogenic transfer and handling technologies

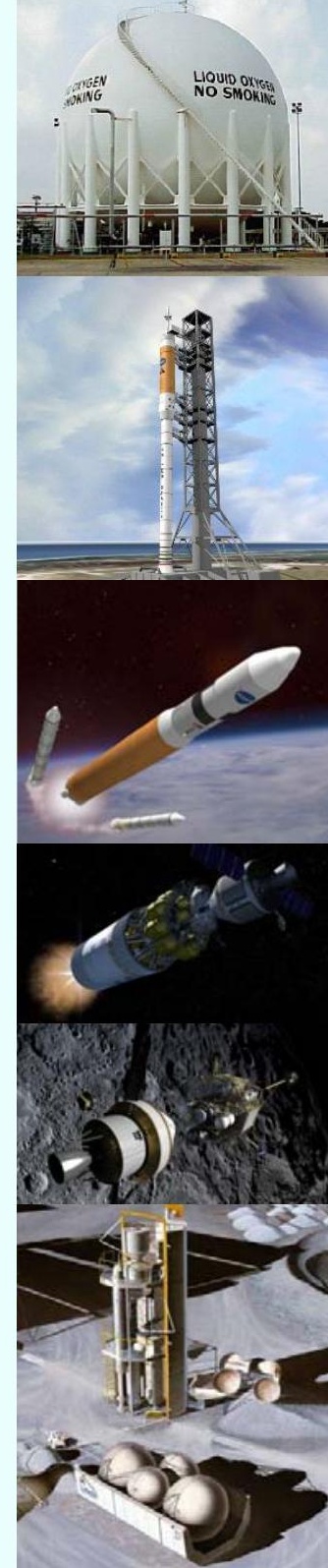




\section{CFM Project Structure}

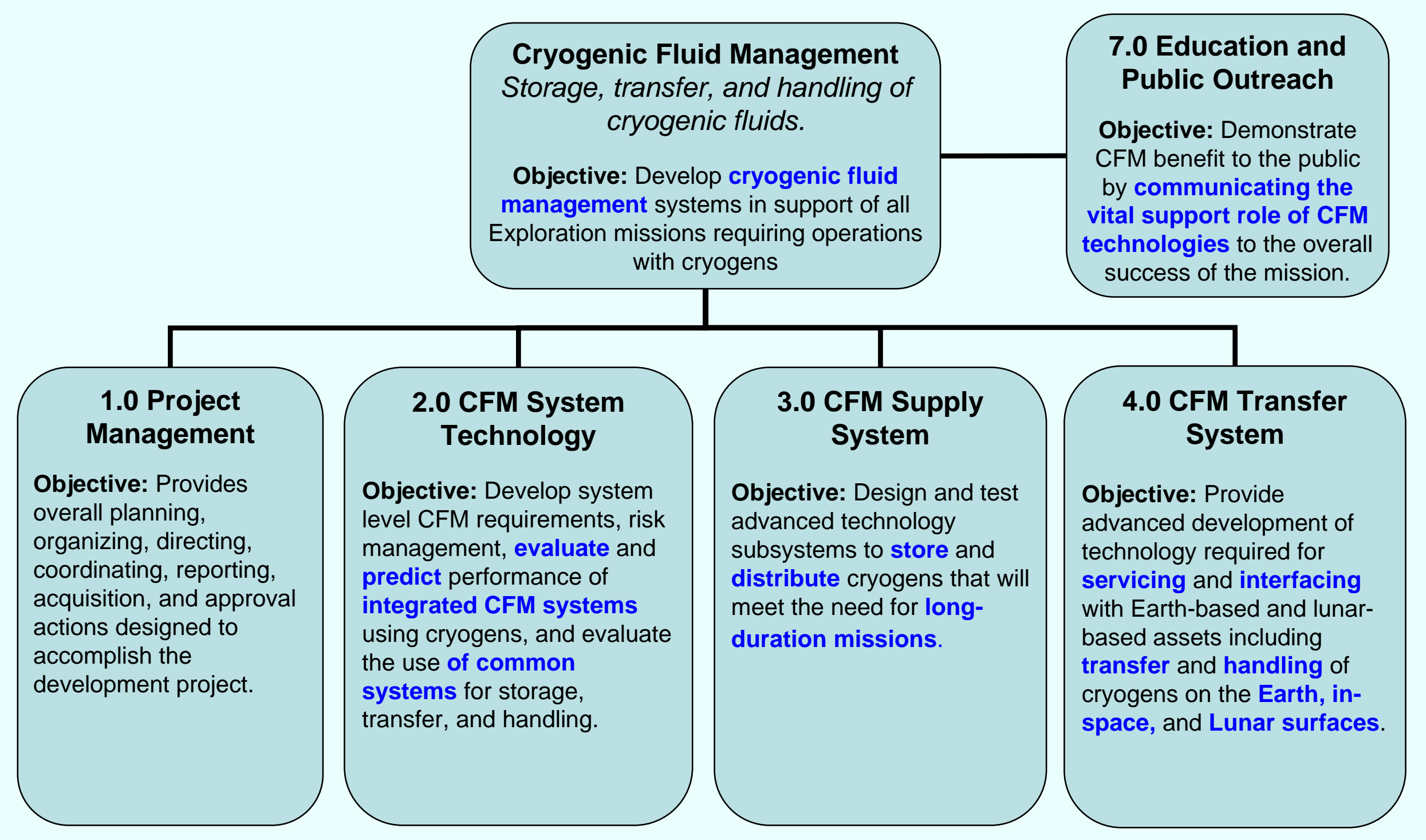


Project Objective: Develop cryogenic fluid management systems in support of all Exploration

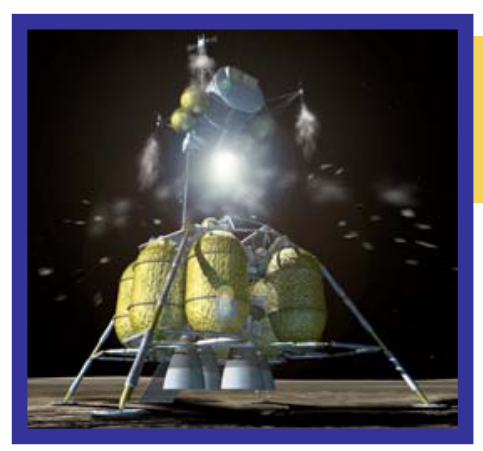
missions requirina in-space and surface operations with crvogens
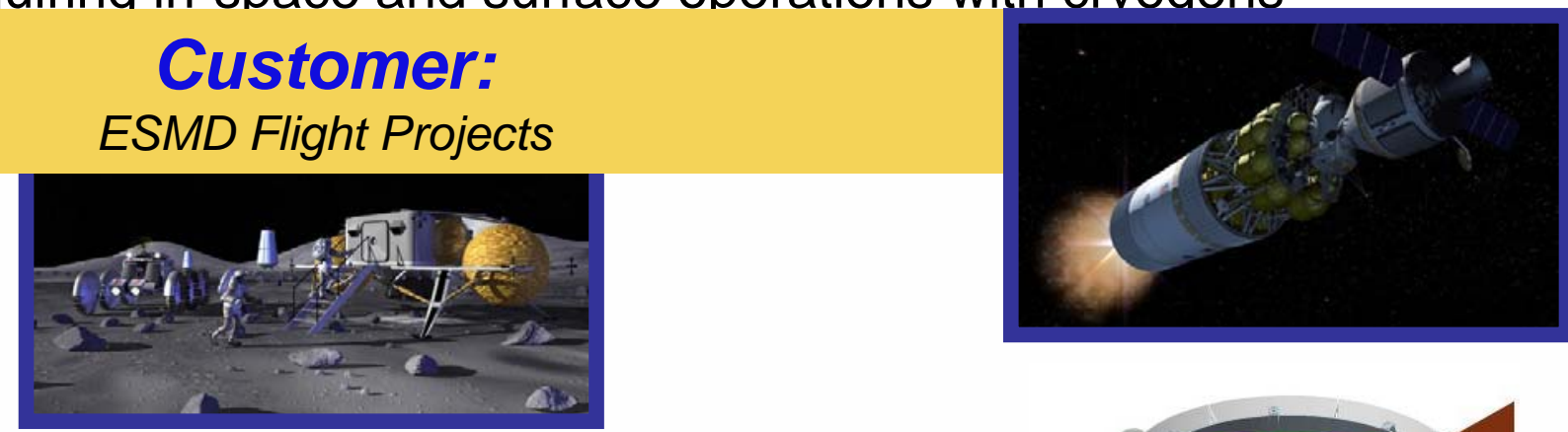

CFM Systems Technology: Evaluate and predict performance of integrated CFM systems using cryogenic propellants, and evaluate the use of common systems for storage and distribution.
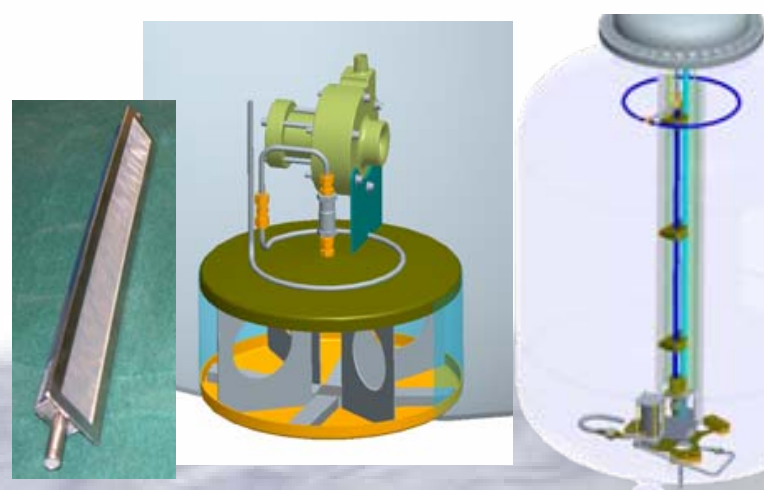

Propulsion Systems CFM Technology: Design and test advanced technology subsystems to store and distribute cryogenic propellants that will meet the need for high-performance propulsion systems on long-duration missions.

Surface Systems CFM Technology: Provide advanced development of technology required for servicing and interfacing with surface assets including liquefaction, storage, and transfer of propellants on the Earth, lunar surface, or transferred in near lunar space.

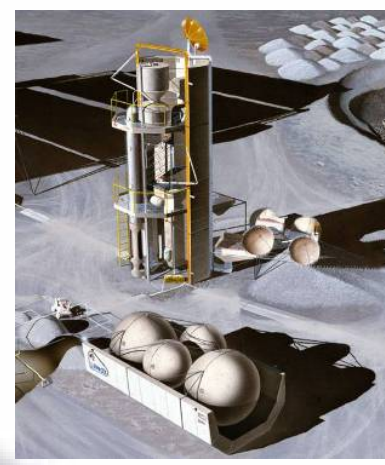




\section{CFM System Technologies}

- Overall CFM Technology Strategy, Technical Integration, Technical Planning

The function of this technology area fundamentally, it is to bring together all system analysis tools and integrated system tests into one place to maximize the synergy and reduce cost.

o CFM requirements; risk management

o CFM systems analyses and trade studies

o CFM evaluation and demonstration of integrated CFM subsystems

o CFM ground test facility management, safety

o Coordination with other ETDP projects and Constellation customers. 


\section{CFM System Technologies}

System Analytical Tools: identify and develop analytical tools to enable the prediction of the integrated performance of CFM components and subsystems under various conditions, and to conduct trade studies of CFM subsystems to assess technology gaps. One is CryoSIM.

- CryoSIM: cryogenic storage system simulation tool the development of which is driven by the need to standardize and integrate a wide variety of existing inhouse cryogenic codes that use a variety of algorithms with varying degrees of documentation, verification, \& availability. Vehicle-level thermal modeling and CFM thermal modeling in one tool

o Build around an industry-standard thermal analysis tool

o Use the best modeling features from existing tools

o Retain legacy modeling capabilities

o Validation and documentation from each contributor

- Consensus in analytical approaches, methods and data

- Centralized version control and archiving

o Flexibility, growth and compatibility with other codes

Platform: Thermal Desktop with RadCAD, FloCAD and SINDA/FLUINT2. Thermal Desktop provides the graphical user interface and conduction network modeling, RadCAD provides the thermal radiation network modeling, and FloCAD provides the fluid network modeling. SINDA/FLUINT is the numerical analyzer.

Capability: system hardware mass estimation, heat leak estimation, boiloff estimation and convective cooling.
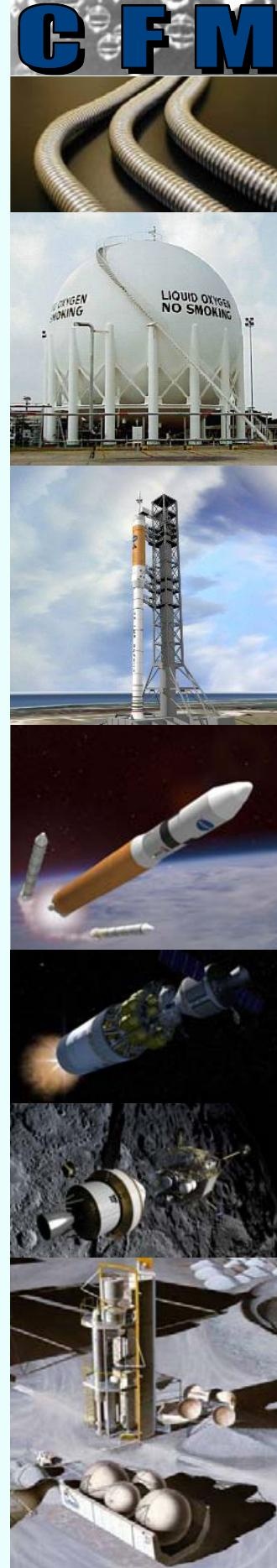


\section{CFM System Technologies}

- Low-G Fluid Dynamics: develop computational fluid dynamic (CFD) models to support prediction of CFM component and subsystem performance for propulsion systems during the dynamic low-g fluid conditions of space.

o Slosh

o Venting

o Interaction of the two

- The short term interest of the project is that of propulsion systems, but in the long term the same concerns apply on the lunar surface.

- The approach for this technology is to develop in parallel in-house NASA capabilities and external capabilities at universities and industry.
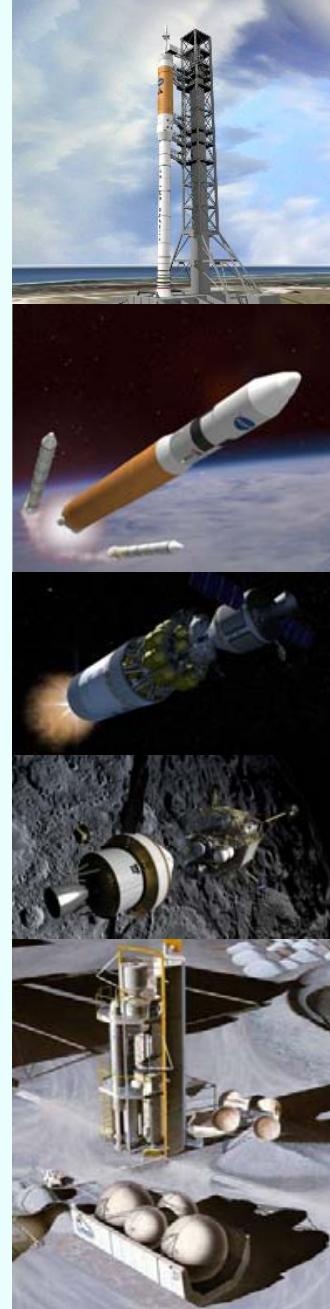


\section{CFM System Technologies}

Integrated Tests and Demonstrations: Two sets of integrated tests/demonstrations are currently planned.

o Integrated tests/demonstrations will be of subscale systems and in some cases they may be close to full scale.

o The accumulation of years of component/subsystem development.

- The best hardware simulation that can be done, short of a system flight test or actual implementation in the launch ground support system.

Integrated Feedsystem Tests: perform thermal vacuum tests with an integrated representative tank CFM-Feed System prototype CFM components/subsystems

o Characterize the interrelationships of these components/subsystem and to validate the integrated performance against the system analytical tools.

- Small Muli-Purpose Research Facility, SMiRF(LCH4), at GRC and two chambers at Test Stand 300 at MSFC (LH2).

Integrated Ground Operations Demonstration: The cost of propellants is based on what is produced at the factory and not what is actually pumped into the launch vehicle at the pad.

o The current capability is atmospheric venting of LH2 and LO2 launch site storage boil off gases replenish with delivery from supplier.

o The goal of this technology is to have zero loss LH2 and LO2 launch site storage and elimination of transfer line fluid heating.

- Technology being consider for development are refrigeration systems to reliquify LH2 and LO2 launch site storage boil off gases, improved LH2 pumping efficiency and transfer line conditioning, and to develop non-invasive transfer line pressure and flow sensors.

o It is planned to integrate refrigeration hardware, pumps and transfer line segment into scaled launch site test facility and conduct ground operation demonstrations.

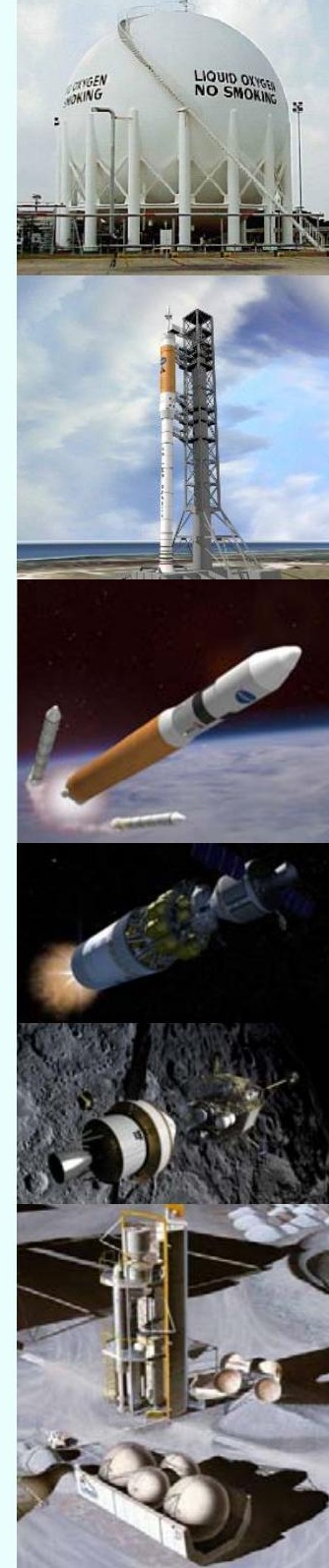




\section{CFM Storage Technologies}

Objectives to design and test advanced technology subsystems to store and distribute cryogens that will meet the need for long-duration missions.

0 1) Liquid Storage to enable the long-term storage of cryogens in one-g and low gravity environments with minimal fluid losses,

- 2) Liquid Supply to provide thermally efficient, delivery of a single phase fluid to the CFM Transfer System

- Instrumentation to enable accurate measurement of cryogenic liquid mass in lowgravity storage tanks without propellant settling, and to enable the ability to detect inspace leaks from the Supply System.

Liquid Storage: development of design tools and models, and components to enable the long-term storage of cryogens in one-g and low gravity environments with minimal propellant losses.

o Thermal control is defined as insulation systems, passive systems, and active systems.

o Pressure Control includes Thermodynamic Vent Systems and mixing

- Analytical models/tools will be used to assess performance of a passive thermal and pressure control system.

Storage component analytical modeling

o create and exercise lumped-parameter analysis models

o develop computational fluid dynamic models using commercial and in-house codes for self-pressurization and pressure control using ground-based experiments.

- Performed in parallel by NASA in-house activities, university activities, and our industry partners.

- Evaluated against existing databases, such as the Saturn 4B test data and recent NASA vacuum chamber test data. (Paper describes the LCH4 testing at MSFC)

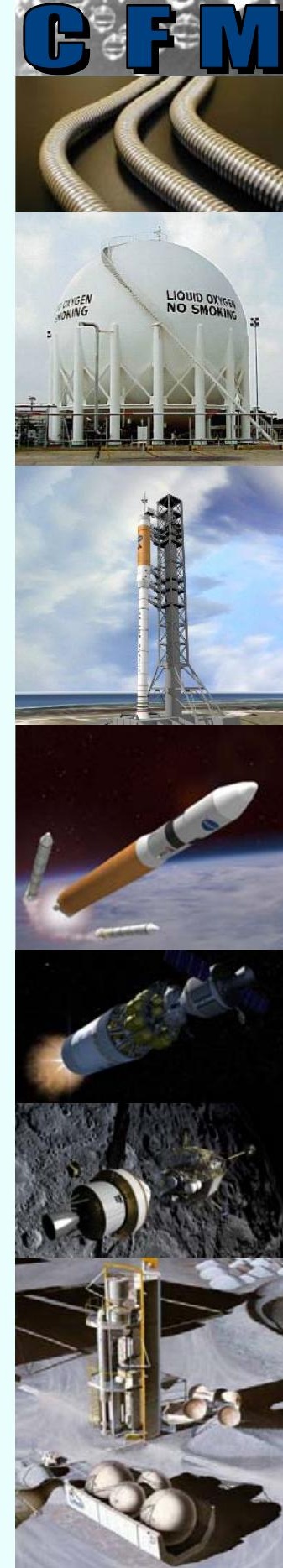




\section{CFM Storage Technologies}

Liquid Supply: provide thermally efficient delivery of a single phase fluid to the CFM Transfer System.

o Development and test of liquid acquisition devices

- Analytical models/tools are developed to assess performance and the mechanical integration of the acquisition devices and pressurization with a test tank under various thermal conditions and mission profiles

In low gravity where fluid is not centered over the tank outlet, withdrawing single-phase fluid becomes a challenge, that is the purpose of the Propellant Management Device, a liquid acquisition device (LAD) takes advantage of capillary flow and surface tension to acquire liquid.

Liquid Supply Instrumentation: enable accurate measurement of cryogenic liquid mass in low-gravity storage tanks without propellant settling, and to enable the ability to detect in-space leaks from the Supply System.

o NASA development and test of RF and PVT (pressure, volume, temperature) low-g mass gauging concepts using a variety of cryogens

- Contractor developed optical mass gauge with LO2

- Leak detection sensors for in-space use and on the ground use. For obvious safety reasons, the earliest detection of any propellant leak allows for the earliest remedy to be applied, or gives the crew the maximum number of options for risk mitigation.

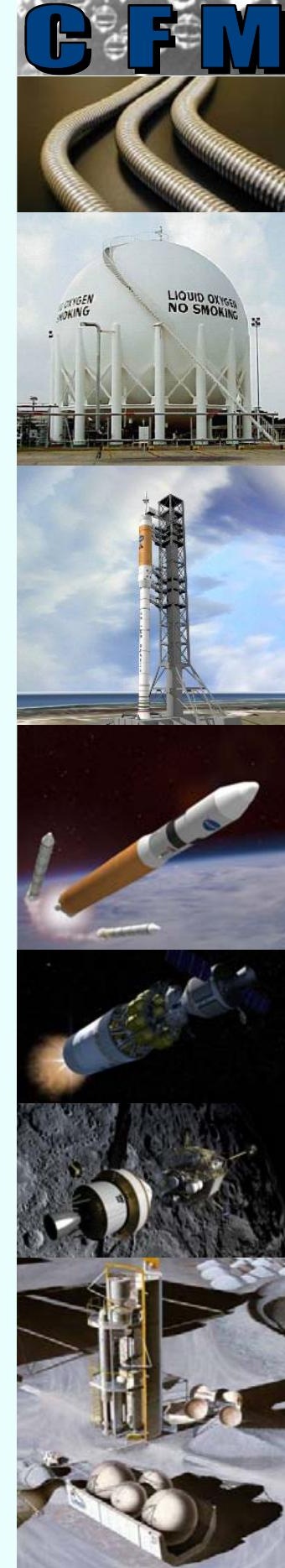




\section{Transfer Technologies}

- CFM Transfer Systems: design and test advanced technology subsystems to transfer and handle cryogens that will meet the need for long-duration missions, and ground systems to support those missions.

$\checkmark$ Liquid Transfer: enable thermally efficient, single-phase, distribution of liquid from the CFM Supply System.

- Cryogenic liquid transfer devices and processes for earth-based, low gravity, and long duration use.

o The project team at JSC has been analyzing and developing technologies for delivering properly conditioned cryogenic propellants to the RCS engine inlet interface through long, small diameter feedlines.

- Cryogen transfer activity is to test quiescent mode cryogenic RCS manifold with TVS to demonstrate that the thermal performance meets or exceeds inlet condition requirements for RCS engines, and to demonstrate feed system feasibility for incorporation into future integrated feed system thruster testing.

Fluid Handling: to process the fluid within the CFM Supply Systems to enable thermally efficient transfer.

o Densification/Subcooling, and Liquefaction

- Manage, design, analyze, develop, and test cryogenic handling processes for earth-based, low gravity, and long duration use.

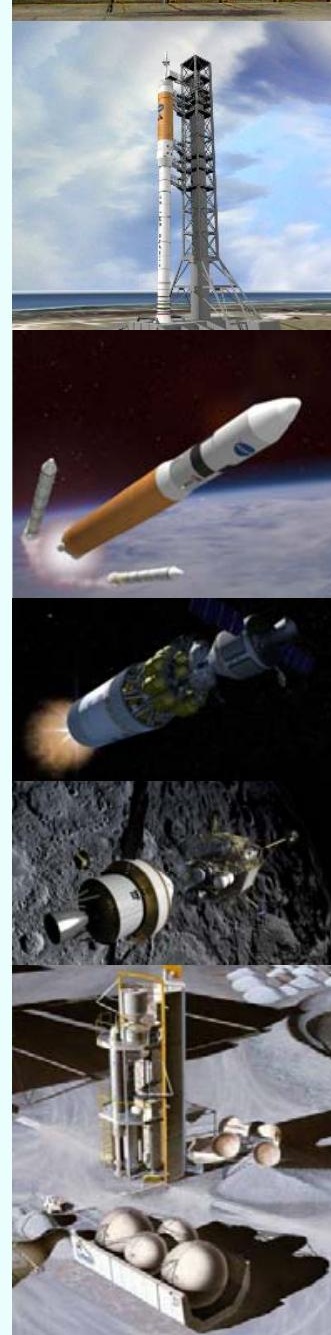




\section{CFM Recent Accomplishments}

One activity in the transfer area is the development of dust-tolerant, minimal loss quick disconnect for cryogenic lines.

$\checkmark$ Objectives is to develop and test a first generation prototype quick disconnect with integrated dust protection and low heat leak, capable of servicing a liquid air extra-vehicular activity suit.

- The recent accomplishments include field testing of mechanical system at Desert Rats and the lab testing of the electrostatic protection technology.
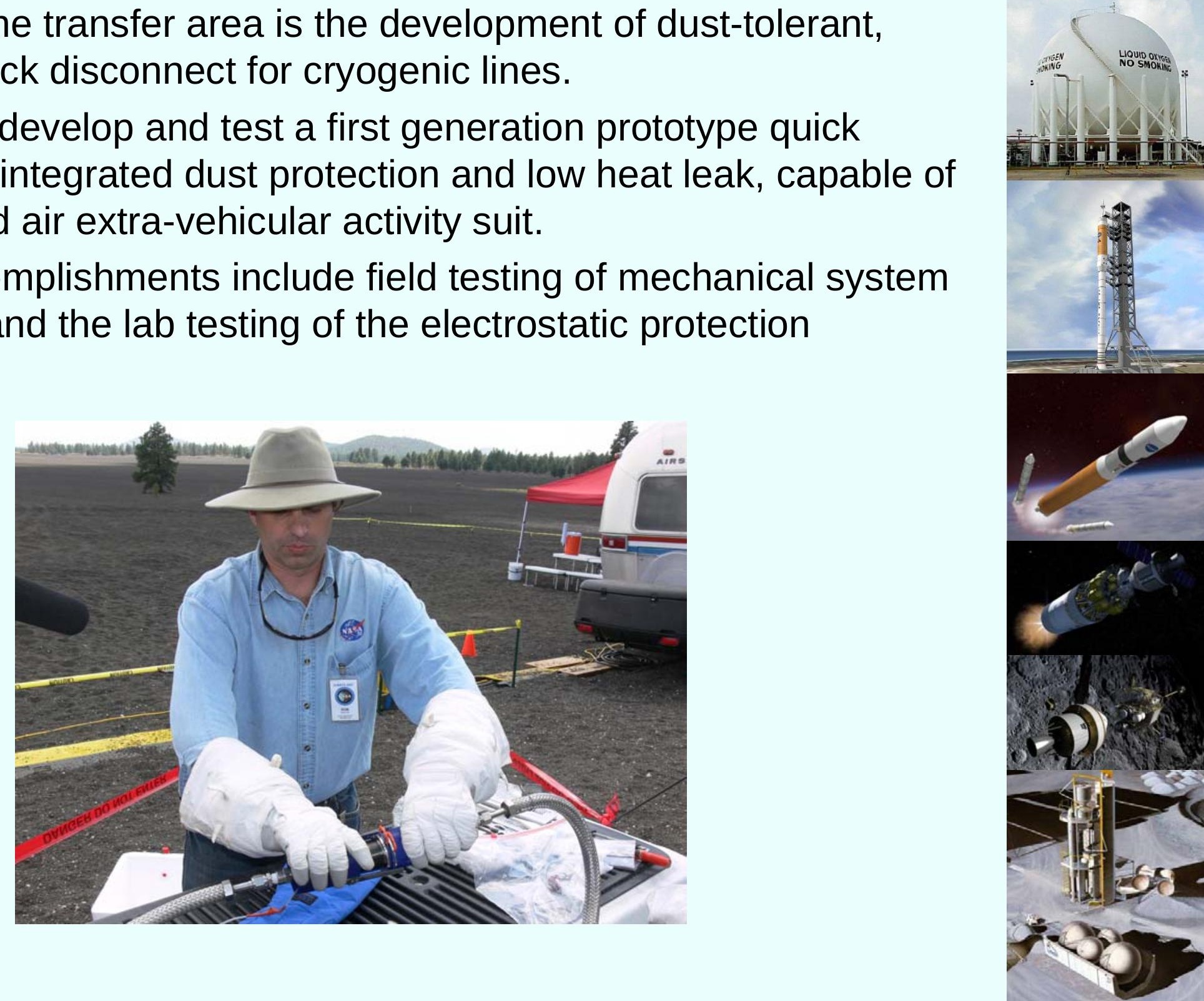


\section{CFM Recent Accomplishments}

$\checkmark$ One recent accomplishment was the completion of the tube to tank test at ARC.

- The test data gathered validated the previously developed broad area cooling modeling correlations for distributed cooling tubes attached directly to cryogenic tank walls.

- The significance of this work is that BAC will allow one or a few single cryocoolers to effectively cool a large cryogenic tank to achieve Zero Boil Off (ZBO) or Reduced Boil Off (RBO) cryogen storage while preventing stratification of cryogen in the tank. This technology is applicable for onorbit, in-space, and lunar/planetary surface applications as well as for scientific missions where the cryocooler is located remotely from the heat load.
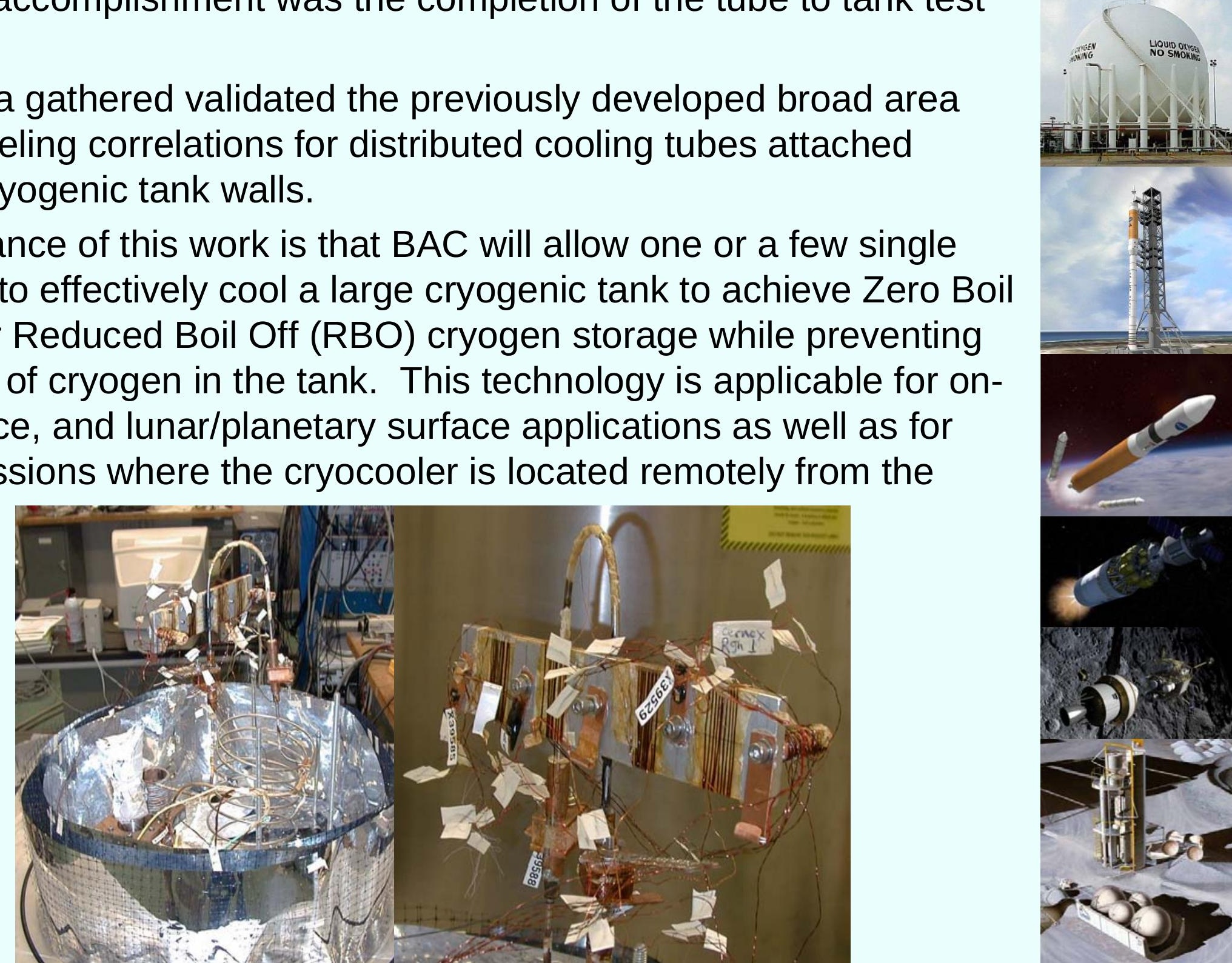


\section{CFM Recent Accomplishments}

Previous tests with LCH4 indicated that the standard method for calculating bubble point appeared to under-predict $\triangle \mathrm{PBP}$ for subcooled $\mathrm{LCH} 4$.

- A kinematic viscosity term had been proposed to improve the correlation between observed test data and predictions, and additional testing over a broader range of fluid conditions was desired.

o Test program with subcooled LO2 was performed to better understand how LAD performance is affected by these factors.

\section{Results from these tests}

o Previously proposed normalized viscosity term is not appropriate.

o Differences between test data and predictions are better explained by considering the LO2 conditions at the screen liquid/vapor interface and the effect of helium pressurant gas on these conditions.

o The significance of these findings points out that the largest potential error in predictions occurs with the coldest liquid, and diminishes as liquid pressures and temperatures increase.

Bubble Point vs Surface Tension
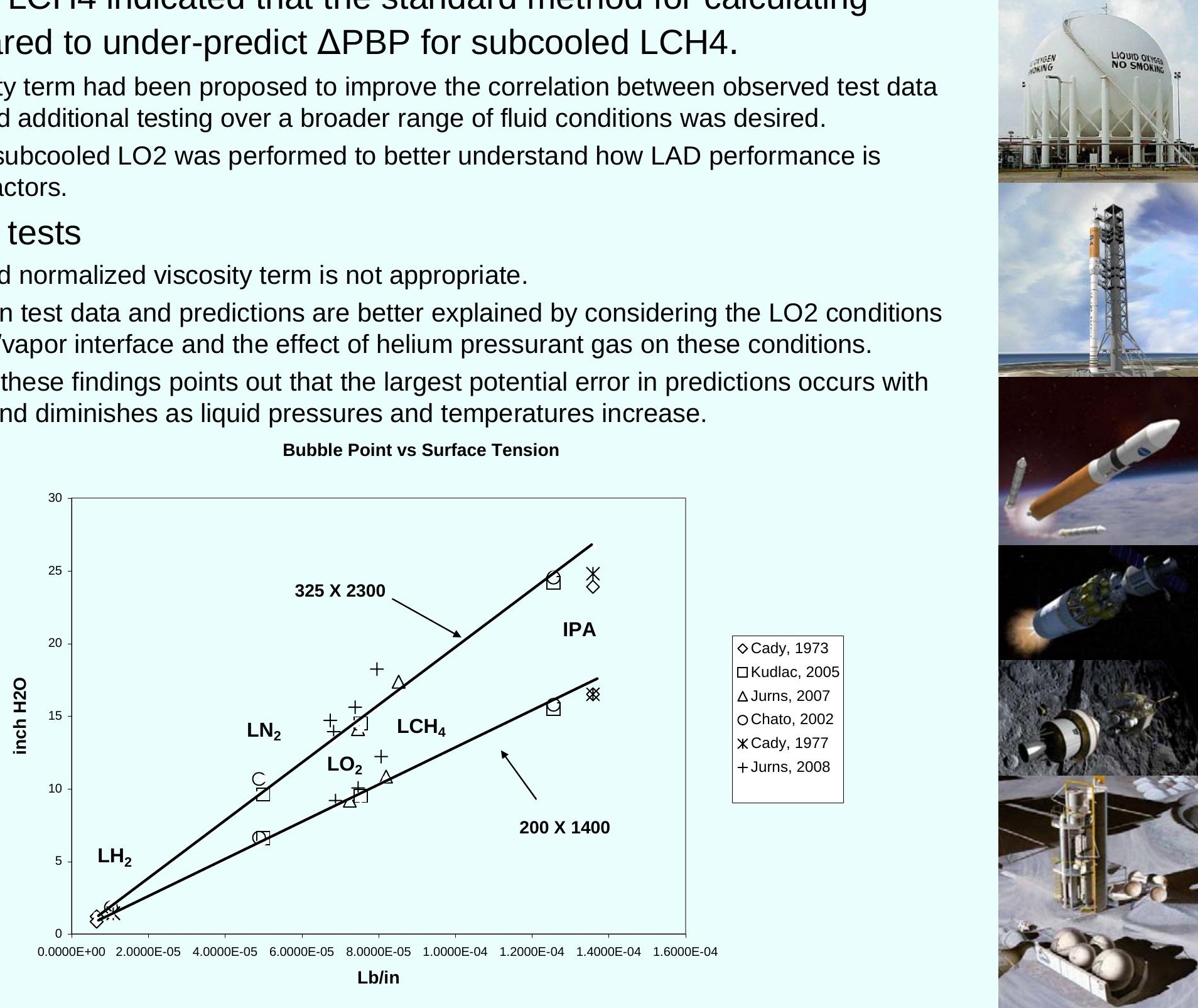
NASA's Cryogenic Fluid Management Technology Project

\section{Questions?}

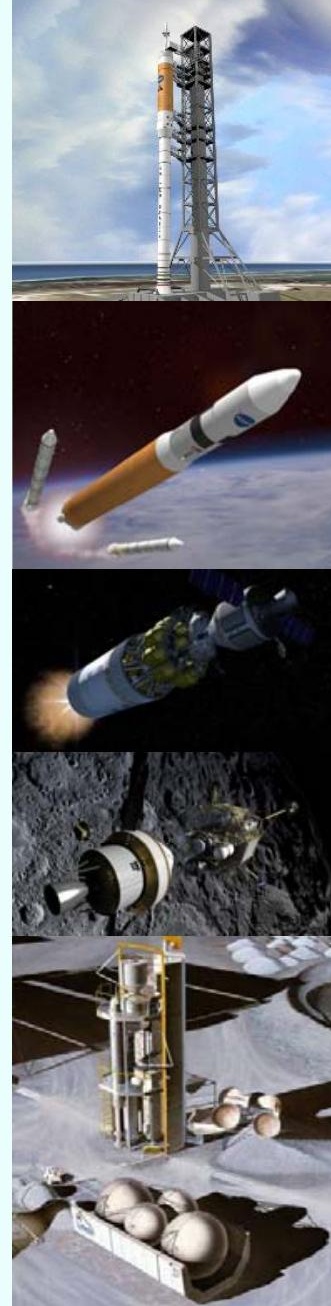

